\title{
A cor do sagrado em Céu sobre água (1978), de José Agrippino de Paula
}

The color of the sacred in Céu sobre água (Sky over water) (1978), by José Agrippino de Paula

El color de lo sagrado en Céu sobre água (Cielo sobre agua) (1978), de José Agrippino de Paula

\section{Cyntia Nogueira ${ }^{1}$}

${ }^{1}$ Universidade Federal do Recôncavo da Bahia, Cachoeira, Bahia, Brasil, cyntianogueira@gmail.com

\section{Resumo}

A partir da ideia de que a cor tem um caráter corporal e táctil, afirmando-se como força, e não como código; presença, e não signo (TAUSSIG, 2009), propomos analisar o curta-metragem Céu sobre água (1978), de José Agrippino de Paula, considerando-o como um ensaio sobre a luz e a cor, com foco na dimensão do sagrado. Através da valorização das formas que surgem das cores e de sua vocação movente, também encontrada na dança e no cinema, o filme integra arte e vida, tendo como eixo o corpo grávido e os movimentos da dançarina e coreógrafa Maria Esther Stockler.

Palavras-chave: Cor. Cultura. Corpo.

\begin{abstract}
From the idea that color has a corporal and tactile character, affirming itself as a force, not a code; presence, and not a sign (TAUSSIG, 2009), we propose to analyze the short film Céu sobre água (Sky over water) (1978), by José Agrippino de Paula, considering it as an essay about light and color, focusing on the dimension of sacred. Through the valorization of the forms which emerge from the colors and their moving vocation, also found in dance and in cinema, the film integrates art and life, having as axis the pregnant body and the movements of the dancer and choreographer Maria Esther Stockler.
\end{abstract}

Keywords: Color. Culture. Body. 


\section{Resumen}

A partir de la idea de que el color tiene un cuerpo y un carácter táctil, afirmándose a sí mismo como una fuerza y no como código; presencia y no signo (TAUSSIG, 2009), proponemos analizar el cortometraje Céu sobre água (Cielo sobre agua) (1978), de José Agrippino de Paula, considerándolo como un ensayo sobre luz y el color, con foco en la dimensión de lo sagrado. A través de la apreciación de las formas que surgen de los colores y de su vocación para el movimiento, que también se encuentra en la danza y en el cine, la película integra el arte y la vida, teniendo como eje el cuerpo embarazado y los movimientos de la bailarina y coreógrafa Maria Esther Stockler.

Palabras clave: Color. Cultura. Cuerpo.

"Color walks. And as it walks, so it changes" ${ }^{1}$

(Michael Taussig)

Céu sobre água (1978), curta-metragem de 20 minutos, foi o último trabalho artístico de José Agrippino de Paula (1937-2007), um dos nomes mais importantes e menos conhecidos do tropicalismo. Autor de Panamérica (1967), livro fundamental para o movimento, além de obras transgressoras no teatro, na dança, no cinema e na música, Agrippino realiza Céu sobre água com a dançarina e coreógrafa Maria Esther Stockler (1939-2006), com quem manteve uma parceria artística e de vida ao longo de mais de uma década. O filme é produzido durante sua gravidez e os primeiros anos de vida da filha do casal, Manhã, no período em que viveram na Bahia.

Definido por Maria Esther como um filme poema ${ }^{2}$, o curta realizado em Super-8 pode ser visto também como um filme de dança e, ao mesmo tempo, um diário íntimo, com registros das vivências do casal entre 1972 e 1978, antes e depois do nascimento de Manhã. É, ainda, um filme processo, que se desdobra no tempo, ao longo dos seis anos em que Agrippino e Maria Esther viveram entre Salvador e Arembepe, após dois anos de autoexílio em países da África como Senegal, Mali, Togo e Dahomey, atual Benim.

Este artigo acrescenta uma outra perspectiva à análise de Céu sobre água, considerando-o como um ensaio sobre a luz e a cor, a partir de uma conexão com o sagrado. Seguindo as sugestões do antropólogo Michael Taussig (2009), propomos pensar a dimensão do sagrado nesse filme a partir da relação estabelecida entre a cor e sua capacidade de invocação. Para o autor, assim como a música, a cor estaria associada a uma 
potência mística, aos fluxos interiores e exteriores do corpo e da imagem, envolvendo não apenas a visão, mas todos os sentidos. Através da cor, seria possível atravessar a imagem e torná-la uma experiência capaz de integrar arte e vida.

Taussig (2009), ao refletir sobre a relação entre as cores e a alteridade, observa que as cores têm a capacidade de dissolver o puramente visual, tornando a imagem algo que pode absorver o observador. Daí o seu caráter profundamente corporal, a sua tactibilidade. A cor, nesse sentido, afirma-se como uma força e não como um código, como presença e não como signo. E estaria fundamentalmente envolvida na construção da cultura a partir do próprio corpo humano.

No filme Céu sobre água, que tem como trilha sonora uma música hindu, um raga atribuído a Ravi Shankar, ${ }^{3}$ os movimentos de Maria Esther se dão em relação às transformações da luz, com a modulação das formas a partir das cores e dos movimentos de seu corpo, da correnteza da água e da câmera. As imagens, assim, tornam-se fluidas, veículos de transformações contínuas em sua relação com os ritmos da natureza.

Alguns comentadores das obras de Agrippino e Maria Esther, que atuaram sempre na fronteira entre as linguagens artísticas, têm chamado a atenção para a dimensão ritualística de suas obras. Arnaldo Antunes, por exemplo, ao comentar o disco Exu 7 encruzilhadas, ${ }^{4}$ gravado em 1971 e descoberto apenas em 2008, afirma que as criações de Agrippino são marcadas pela busca de um elo entre culturas milenares e contracultura, experimentalismo e ancestralidade, transe e ritualização da experiência; e, por fim, de uma estética e de uma religiosidade próprias.

Observamos que, em Céu sobre água, essa busca é potencializada pela convergência entre as pesquisas de Maria Esther com o corpo e a dança ritual e as investigações de Agrippino em torno das propriedades da luz e da cor, a partir da aquisição de uma câmera Super-8, dentro de um espectro de vivências e práticas artísticas caracterizadas por uma conexão profunda entre arte e vida.

A partir dos reflexos do céu sobre a água e dos movimentos do corpo nu de Maria Esther, primeiro grávida e, depois, com sua filha, no rio Caratingui, Agrippino capta, com sua câmera, a experiência de busca desse casal de artistas por liberdade e por uma arte conectada com uma dimensão ritualística, que tem como ponto de partida o ideal de transformação pessoal e coletiva através da reinvenção dos modos de vida, da relação com a alteridade e da defesa de bandeiras como o pacifismo, o feminismo e o ambientalismo, que marcam o movimento da contracultura de forma mais ampla (RISÉRIO, 2005). 
Por outro lado, buscamos aproximar a experiência de Agrippino, com sua Super-8, às pesquisas que marcaram a pintura impressionista e a observação da luz como um dado perceptivo, variável, entre objetividade e subjetividade. Ao valorizar as formas que surgem a partir das cores e sua vocação movente, também encontrada na dança e no cinema, Agrippino e Maria Esther parecem cruzar mais uma vez as fronteiras das linguagens, fazendo do ritual da criação artística, assim como o da gestação, o próprio recomeçar de um mundo.

\section{Panaméricas de Áfricas utópicas}

José Agrippino de Paula e Maria Esther Stockler tiveram trajetórias artísticas e de vida incomuns. Artista multimídia avant la lettre, nascido em São Paulo e tendo estudado arquitetura no Rio de Janeiro, Agrippino escreveu os romances Lugar público (1965) e Panamérica (1967), além da peça Nações Unidas (1967), antes de criar, em 1968, com Maria Esther, o grupo Sonda.

Sobre Panamérica, citado na música Sampa, Caetano Veloso (1997, p.103) afirmaria, em sua autobiografia Verdade tropical, que o livro apresentava uma "técnica de narração por imagens" fundamental para o surgimento do tropicalismo. Segundo Yann Beauvais (2009), enquanto em Panamérica (e também na peça Nações Unidas), Agrippino apropriava-se, à maneira da pop art, de ícones do cinema de Hollywood e da música popular anglo-saxã para desmontar, através do excesso, os mitos da indústria cultural, em Lugar público, visto como um romance de formação, o artista multiplicava as descrições das paisagens urbanas de uma cidade latino-americana em meio a rápidas transformações, tendo como eixo central as inquietações de jovens e suas descobertas sexuais sem lugar frente à forte violência do Estado no contexto pós-64 no Brasil.

Agrippino conhece Maria Esther entre 1964 e 1965. A cena é descrita pelo próprio artista. De acordo com seu relato, ela dançava uma música hindu de Ravi Shankar, quase numa postura de meditação, num ensaio do grupo de dança Móbile, ${ }^{6}$ no estúdio de Roberto Aguilar, ponto de encontro de artistas e intelectuais da vanguarda paulistana na época. O grupo, criado em 1964, era fruto de uma parceria entre Maria Esther e Maria Duschenes, discípula de Rudolf Laban e com quem tinha iniciado seus estudos em dança moderna em 1954, ainda morando no Rio de Janeiro. Em 1965, ela apresenta, com o Móbile, um solo chamado Improvisação sobre um tema de raga da noite, com música clássica hindu interpretada por Ali Akbar Klan. O interesse pela cultura oriental 
vinha desde a adolescência, quando começa a estudar ioga, algo ainda pouco comum. A prática a acompanharia durante toda a sua vida.

Não à toa, chama atenção o fato do artista ter escolhido um raga do mesmo compositor para a trilha de Céu sobre água, um ritual de celebração da criação, mas, também, o diário íntimo de uma relação afetiva, familiar, marcada por uma profunda comunhão entre os territórios da existência e da realização artística.

Quando conhece Agrippino, Stockler tinha acabado de retornar dos Estados Unidos, onde aprofundou seus estudos em psicologia e teve a oportunidade de frequentar, em Nova York, os estúdios de dança moderna de Martha Graham, Merce Cunninghan, Alwin Nikolais, entre outros. Nesse período, manteve contato com artistas do coletivo Judson Dance Theater e da companhia The Living Theatre, criada por Judith Malina e Julien Beck. Com isso, traz para suas criações o conceito de mixed media e a experiência vivida em meio à efervescente cena da pop art norte-americana, marcada pela emergência de formatos artísticos como as performances, instalações e happenings, os quais de certo modo já estavam virtualmente presentes na literatura de Agrippino.

Segundo Julia Giannetti (2015), os dois espetáculos montados com o Móbile, em 1964 e 1965, impulsionam suas criações como solista e coreógrafa, pavimentando a atuação pioneira no Brasil como preparadora corporal para o teatro. Maria Esther assinaria, dois anos depois, a coreografia da célebre montagem de $O$ Rei da Vela (1967), de Oswald de Andrade, dirigida por José Celso Martinez Corrêa, no Teatro Oficina, marco do teatro tropicalista com trilha sonora de Caetano Veloso, Damina Cozella e Rogério Duprat.

A partir de 1968, com o grupo Sonda, Maria Esther e Agrippino expandem os limites da dança, do teatro, da música e das artes visuais com o espetáculo Tarzan do III Mundo - O Mustang hibernado. A montagem aprofunda, de acordo com Beauvais (2009), o que chama de pop fantástico. Com um elenco de atores amadores, coreografia e preparação corporal de Maria Esther, a peça é estruturada em cinco cenas, cada uma sob responsabilidade de um artista plástico, com uma concepção inovadora dos cenários, figurinos e efeitos técnicos de iluminação e sonoplastia. Agrippino adota o conceito de collage como um princípio estético, privilegiando a justaposição e a simultaneidade de blocos autônomos, mais ou menos autobiográficos, e o diálogo com a linguagem cinematográfica a partir do princípio da montagem. Para Beauvais (2009, p. 252), tratase de uma crença na "potência fabuladora da imagem", em sua capacidade de amplificação e multiplicação, a partir de um modo de fazer coletivo que irá recolocar o corpo do artista em primeiro plano (MORAES, 2011). 
Com o grupo Sonda, José Agrippino e Maria Esther acionavam, no sentido deleuziano, uma máquina de criação coletiva, que resultaria, no mesmo ano, no longa-metragem Hitler de III Mundo (1968). Dirigido por ele, o filme foi realizado com sobras de negativos e equipe mínima, reunida sempre às pressas. Os atores improvisavam performances no espaço público da cidade de São Paulo, tendo como ponto de partida uma das cenas escritas por ele para O Mustang hibernado. No filme, exibido pela primeira vez apenas em 1984, após a ditadura militar, a autonomia da trilha, fora de sincronia com as imagens e feita a partir de diferentes matérias sonoras, reforça a ideia de uma linguagem feita de blocos de cenas que opõem-se e confrontam-se, motivando uma polifonia de vozes e ações.

Essas estratégias também estão presentes na concepção cênica do show $O$ planeta dos Mutantes (1969), da banda Os Mutantes, e do espetáculo Rito do amor selvagem (1969), um marco no teatro de vanguarda brasileiro. No programa deste último, Agrippino define de forma mais explícita a proposta do grupo, a partir de noções como mixagem e arte-soma, feita de componentes heterogêneos que produzem montagens simultâneas, sem hierarquia entre linguagens artísticas ou temporalidades históricas. Daí vem o sentido ritual, a arte pensada como um fazer coletivo, que se destina também à construção de devires coletivos:

O objetivo coletivo nasce livremente e contém em si todas as manifestações coletivas que historicamente estão integradas em nós: o show, a dança, o teatro, o circo, o happening, o cinema, os rituais, nas suas formas mais arcaicas, primitivas e contemporâneas (apud MORAES, 2011, p.11).

Para Felipe de Moraes, o espetáculo Rito do amor selvagem teve impacto semelhante ao do livro Panamérica, concretizando princípios estéticos que já estariam presentes em suas obras anteriores. A peça Nações Unidas, que serve de referencial para a montagem, é utilizada apenas como dispositivo para a improvisação dos atores e atrizes, sendo Stênio Garcia o único profissional. Construída a partir de "ações e incidentes, escolhas e acasos, esferas autônomas que se inter-penetram ou se repelem" (MORAES, 2011, p.96), numa soma de performances e acontecimentos, a obra recusava programaticamente qualquer forma de totalidade, afirmando a arte não como um lugar de representação, mas de construção de mundos.

Nesse sentido, cabe citar aqui, mais uma vez, Yann Beauvais (2009, p.260261), em sua observação de que, nas obras de José Agrippino de Paula, "as coisas 
ajustam-se mais do que são atribuídas, designadas; estão sempre no fluxo e neste sentido provocam uma transformação constante da percepção, ou mais ainda manifestam esta transformação como processo do fluxo". Recorrendo à ideia de metaformose em Foucault, vista como uma forma de enganar a morte através da passagem de uma figura à outra, observa que as mutações da imagem em Agrippino são uma maneira de resistir às imagens da indústria cultural, multiplicando-as e transformando-as através da fabulação e da imaginação.

É interessante pensar esse conceito de metaformose da imagem em relação a Céu sobre água, tendo em vista agora não mais os ícones da indústria cultural, mas as transformações das cores, geradoras de novas formas na relação com os movimentos, as mudanças da luz e o corpo de Maria Esther, dentro de uma poética bastante distinta desses trabalhos, ${ }^{7}$ mas que ainda assim mantém uma enorme coerência com as inquietações e as investigações artísticas que pautaram as obras construídas por ambos com o grupo Sonda.

Em 1970, com o acirramento da censura e da repressão do Estado durante a ditadura militar, Agrippino e Maria Esther decidem ir para a África, passando por países como Senegal, Mali, Togo e Dahomey (atual Benim), onde realizam os filmes de curta e média-metragens em Super-8 Candomblé do Togo (1972), Candomblé do Dahomey (1972) e Maria Esther: danças na África (1972), antes de chegarem à Bahia. Todos esses trabalhos, assim como Céu sobre água, inserem-se dentro da tradição do filme de dança e podem ser considerados, de certa maneira, precursores da videodança no Brasil. A partir da África, Agrippino e Maria Esther, grávida, descobrem Salvador, na Baía de Todos os Santos, do outro lado do Atlântico, refazendo um dos principais trajetos da diáspora africana no Brasil. ${ }^{8}$

\section{Dança ritual e metaformoses da imagem}

Muitos são os relatos que dão conta da passagem quase mítica de Maria Esther e Agrippino por Salvador. A opção por viver na lendária praia de Arembepe, conhecida por sua aldeia hippie às margens da lagoa do rio Caratingui, para onde convergem artistas do mundo inteiro, reforçaria o distanciamento de ambos das dinâmicas do circuito de produção de espetáculos, com o aprofundamento de uma atitude artística que percebia a política como necessariamente ligada às práticas cotidianas. 
Durante o tempo em que percorrem os países do continente africano, Maria Esther amplia seu interesse pelas danças rituais e pela pesquisa corporal relacionada ao conhecimento de outras culturas, buscando um contato sagrado com a dança. No média-metragem Maria Esther: danças na África (1972), Agrippino faz uma espécie de registro doméstico de suas improvisações diárias. Ao longo de 40 minutos, vemos a dançarina, com o torso nu, executar movimentos de ioga, dança clássica hindu e de rituais religiosos africanos no espaço interno de casa, permeável à paisagem externa, em alternância com cenas cotidianas de comunidades onde viveram. É como se Agrippino redimensionasse o filme de família, tão comum ao Super-8, associando ao registro do espaço íntimo, doméstico, o filme de dança. Por outro lado, aprofundava seu interesse pelo candomblé e pelas músicas ligadas aos rituais de possessão, "em suas batucadas sagradas, sempre iguais e diferentes, seus infinitos significados e variações," 9 explorando as potencialidades da imagem granulada, de cores saturadas e poucas variações cromáticas da câmera Super-8, uma Canon 814, que o casal adquire antes da viagem.

Com essa câmera, Agrippino filma cerca de cinco horas de imagens em movimento, registrando o cotidiano e os rituais religiosos em pequenas comunidades no Togo e no Dahomey, a partir de uma perspectiva bastante pessoal e de uma abordagem coreográfica, em que a câmera parece "dançar" com os sujeitos filmados. O filme apresenta um caráter imersivo, em que a câmera assume, muitas vezes, o ponto de vista subjetivo de personagens em transe, numa proximidade visceral com esses corpos. A visualidade é construída através da explosão de cores, como verde e o vermelho, ou do contraste entre o branco e o preto, produzindo no espectador uma forte sensorialidade, de forma a inseri-lo nas imagens.

Se em Hitler do III Mundo Agrippino se encarregava da concepção das performances dos atores no espaço público, filmadas livremente por Jorge Bodansky, ${ }^{10}$ construindo o filme a partir de happenings e de uma montagem entendida como mixagem de elementos heterogêneos, com a Super-8 apropria-se de sua tactibilidade e sua manuseabilidade características, explorando sua forte corporeidade. As cores quentes, vivas, contrastadas, e a granulação apontam para a materialidade do meio e imprimem à imagem um efeito de suspensão do tempo. Trata-se de uma imagem que não adere diretamente ao real e torna-se imprecisa como a memória.

Com os filmes realizados no Togo e Dahomey, Agrippino iniciava suas pesquisas sobre a luz e a cor, preferindo filmar sempre depois das três da tarde, quando, dizia, era possível captar uma luz mais difusa, sem sombra. Buscava, assim, equilibrar a forte 
saturação da câmera Super-8 diante da luz tropical e do colorido dos tecidos que, segundo Tom Zé, podem ser vistos, com suas formas geométricas, quase como panejamentos-linguagens. ${ }^{11}$ Os movimentos dos corpos nesses rituais sagrados são captados pelo olhar de Agrippino e pelo sentido coreográfico da câmera de Maria Esther, que, segundo ele, era quem conseguia captar o ritmo das danças rituais.

Essas investigações, associadas à ritualização da dança na vida cotidiana, postura adotada por Maria Esther em sua busca por espaços de liberdade e de emancipação feminina, o que passa necessariamente pela questão do corpo, da sexualidade e da relação com a alteridade, serão fundamentais para a realização de Céu sobre água. Vale lembrar que antes de chegar à Bahia, o casal havia participado de alguns workshops em Londres, um deles de kathakali, um tipo de dança do sul da Índia, de Kerala, que explora movimentos leves e lentos, que nascem e baseiam-se no olhar e nos pés, com a utilização de máscaras coloridas. Nessa época, segundo depoimentos recolhidos por Julia Gianetti (2015), Stockler costumava passar horas dançando ao som de Ravi Shankar. Já durante o período em que moraram entre Salvador e Arembepe, em 1976, Maria Esther fez uma viagem com sua filha, ainda pequena, para conhecer rituais indígenas da Amazônia peruana, onde gravou imagens em vídeo para um filme, Mãe Terra, nunca finalizado. Todas essas experiências seriam, de certo modo, incorporadas à realização de Céu sobre água.

Com esse filme, Agrippino tem a possibilidade de aprofundar a sua pesquisa em torno das cores, acompanhando, à maneira dos pintores impressionistas, as variações da luz na natureza, de acordo com determinados horários do dia. Beto Hoisel (2003), em seu livro de memórias, ${ }^{12}$ conta que um dia encontrou Agrippino e Maria Esther filmando bem cedo no rio Caratingui. Ele relata que Agrippino procurava captar a luz a partir de um determinado ângulo do sol, buscando registrar uma cor específica que só aparecia naquele horário. Provavelmente, os tons violeta, muito presentes no filme, e que podem ser vistos com mais frequência durante as primeiras horas da manhã, antes de se misturarem ao azul.

Segundo Hoisel, Agrippino gravou um take único de três minutos sem nenhum corte, concluindo logo em seguida as filmagens. Ou seja, interessava efetivamente a luz captada naquele instante e não em outro. Naquele encontro, Maria Esther, grávida, teria revelado que a filha do casal se chamaria Manhã, e Agrippino que o filme poderia ter o título de Luz da Manhã. Provavelmente essas foram algumas das primeiras imagens realizadas para Céu sobre água, que em determinado momento exibe, nas águas em movimento do Caratingui, sua paleta de cores: uma gradação suave de amarelos quase translúcidos, que refletem os raios solares, e, especialmente, os violetas e os azuis. 
No filme, o autor usará as cores e os reflexos dos movimentos e dos corpos na água para produzir novas metamorfoses da imagem. Entre os registros de cenas cotidianas ao redor do rio Caratingui e dos corpos nus de Maria Esther e Manhã integrados à paisagem, surgem imagens em que as formas perdem contornos e definição, tornando-se conjuntos de cores que, associadas aos movimentos lentos da dançarina e às vibrações dos intervalos microtonais do raga, ${ }^{13}$ invocam, como nos faz pensar Taussig (2009), uma conexão com o sagrado.

\section{A cor do sagrado em Céu sobre água}

No primeiro plano de Céu sobre água, as pernas de Maria Esther emolduram o céu. É uma imagem desconcertante, não apenas pelo ponto de vista, que coloca em primeiro plano o seu sexo, exibindo seus pelos pubianos e suas pernas no alto, que se abrem lentamente desvendando o azul celeste, mas também pela desterritorialização em relação ao espaço. Demoramos um pouco a compreender o que vemos, enquanto o raga indiano e suas variações microtonais nos colocam no território místico.

$\mathrm{Na}$ postura da vela típica da ioga, Maria Esther executa movimentos lentos, abrindo e fechando as pernas iluminadas lateralmente, ora enquadrando o céu azul, ora desestabilizando o quadro, movendo-se de frente e de costas, enquanto o plano continua na altura de sua pelve, primeiro exibindo o monte de vênus, depois suas nádegas. A câmera então registra diretamente a luz do sol, que invade o quadro, para mostrar, em seguida, imagens cotidianas de crianças e adultos tomando banho e nadando nus no rio. Maria Esther, grávida, surge entre eles, boiando na água. O seu corpo é apresentado horizontalmente; e as curvas de seu sexo, barriga e seios ocupam o plano, tendo ao fundo o azul da água e do céu, entre dunas e coqueirais.

O corpo de Maria Esther é filmado, assim, como parte da paisagem.

Girando em torno de seu corpo, reinserido em meio aos banhistas, a câmera capta sua barriga flutuando para logo em seguida registrar o reflexo distorcido de seu rosto parcialmente submerso. Para além da duplicação de sua imagem, observa-se especialmente as variações das formas e das cores, que ganham vida elas mesmas, gerando outras formas, em meio à densidade e à fluidez da água. É como se as pequenas ondas que reverberam a partir dos movimentos de Maria Esther sob a luz pudessem ser vistas como matéria-prima para pinturas instáveis, fotocromáticas, feitas de camadas moventes de cores. É dessa matéria-prima que Agrippino parece construir o seu filme. 
Figura 1

O corpo de Maria Esther é apresentado como parte da paisagem. Na segunda

figura, a distorção da imagem na água forma camadas moventes de cores.

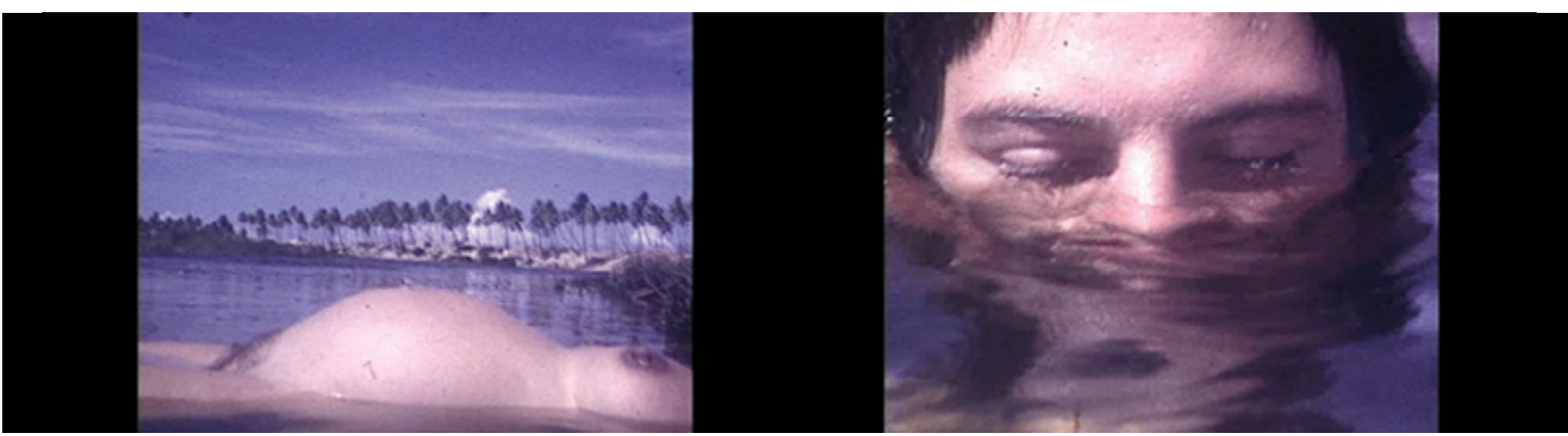

Fonte: Céu sobre água, 1978, 20min28s.

Para Taussig, o mistério da cor - e também a sua repulsa pelo mundo ocidental - vem justamente de seu sentido deslizante, movente, vivo. Em sua visão, o desejo de controlar a cor equipara-se, historicamente, ao esforço de controlar o “outro", ou os "outros" da narrativa moderna. Nesse sentido, a cor é vista como um "excesso" que permite às formas se tornarem vivas, ou, dito de outro modo, que anima as formas: “A cor anda. $\mathrm{E}$ ao andar, ela muda. Não se trata de um borrão dentro de uma figura preexistente, preenchendo uma forma, porqueas cores têmasuaprópria 'forma', dandovida eluzao mundo" (TAUSSIG, 2009, p.36).

Em Céu sobre água, Agrippino parece justamente reivindicar essa dimensão mágica da cor, que dá vida às formas assim como o corpo da mulher a uma criança, a um novo ser, a um novo mundo. Antes da primeira aparição de Manhã, refletida num espelho com o céu azul no fundo, o filme apresenta uma sequência de solos de Maria Esther. Uma multiplicidade de formas é criada a partir dos movimentos das cores, da luz e de seu corpo nas águas ora douradas, em superfícies rasas, ora densas de azuis escuros quase pretos. O corpo então desmaterializa-se, impregnado, por instantes, por amarelos vivos, que ganham densidade, espessura e luminosidade.

Com foco por vezes nos movimentos das mãos, por vezes das pernas, José Agrippino de Paula capta a luz como quem pinta um quadro, criando camadas de tonalidades fotocromáticas e direcionando a luminosidade de maneira a enfatizar a força movente da cor. Parece nos dizer, com Taussig, que "quando vemos uma cor, estamos vendo na 
verdade um jogo com a luz dentro, através e sobre um corpo, o corpo mesmo da cor" ${ }^{15}$ (TAUSSIG, p.42, tradução nossa).

\section{Figura 2}

Ao captar a luz a partir dos movimentos das mãos de Maria Esther na água, Agrippino enfatiza a corporeidade e a força movente da cor.

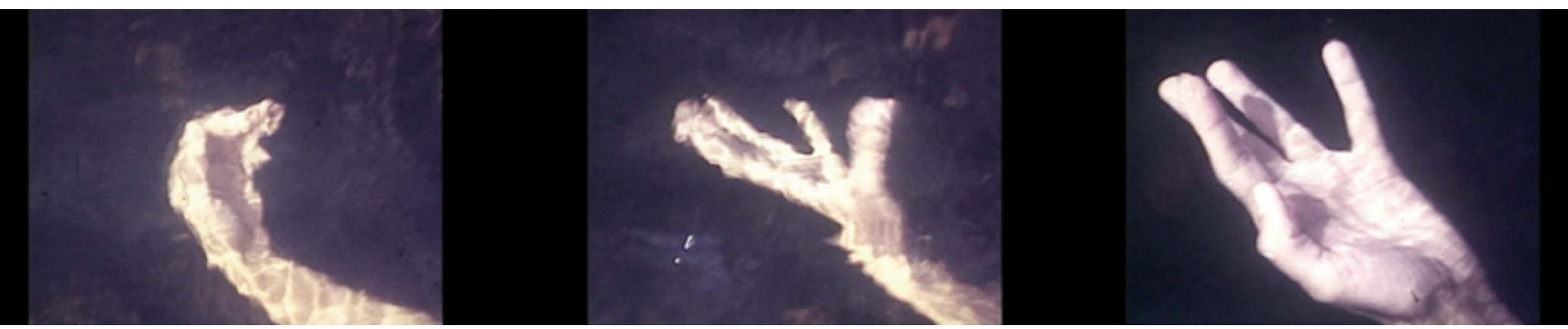

Fonte: Céu sobre água, 1978, 20min28s.

As cores parecem nos conduzir ao que Eduardo Viveiros de Castro chama de metamorfose mítica, ou seja "um acontecimento, uma mudança não-espacial: uma superposição intensiva de estados heterogêneos” (2015, p.15), que se coloca, portanto, fora da história. Trata-se, de acordo com o autor, a partir do que chama de perspectivismo ameríndio, de uma figura ou, melhor, uma figuração do devir:

O que define os agentes e os pacientes dos sucessos míticos é, precisamente, sua capacidade intrínseca de ser outra coisa; neste sentido, cada personagem difere infinitamente de si mesmo, visto que é posto inicialmente pelo discurso místico apenas para ser substituído, isto é, transformado. Esta "auto-diferença” é a propriedade característica dos agentes cosmológicos que designamos "espíritos"; por isso, todos os seres míticos são concebidos como "espíritos" (e como xamãs), assim como, reciprocamente, todo existente atual ou "modo finito" pode se revelar agora, porque foi antes, um espírito, uma vez que sua razão de ser encontra-se relatada no mito. A suposta indiferenciação entre os sujeitos míticos é função de sua irredutibilidade constitutiva a essências ou identidades fixas, sejam elas genéricas, específicas ou mesmo individuais. (VIVEIROS DE CASTRO, 2015, p.57)

Viveiros de Castro nos oferece uma chave interessante para pensar as metamorfoses da imagem em Céu sobre água em sua relação com a natureza e o sagrado. Mais do que a ideia de "um retorno à natureza”, segundo uma perspectiva que coloca, de um lado, 
a narrativa da modernidade e sua racionalidade científica e, do outro, o "homem em estado da natureza”, visto como primitivo, selvagem, não civilizado, atrelado a um passado irreversível, trata-se antes de reivindicar, como aponta Taussig, a partir de Michel Leiris, ${ }^{16}$ um reencantamento do mundo.

O conceito de metamorfose mítica contrapõe-se, assim, à ideia de uma história linear, reclamando a presença de um espírito-força do sagrado (TAUSSIG, 2009) no cotidiano e, ao mesmo tempo, a busca pelo reconhecimento de identidades e subjetividades descentradas, ou desterritorializadas, em relação aos cânones da modernidade ocidental.

Nesse sentido, é importante perceber como o filme alterna momentos de desmaterialização e dissolução do corpo na imagem a outros em que este ganha novamente contornos e linhas definidas, bem como de registros quase documentais de cenas cotidianas da vida em Arembepe. É como se fossem duas dimensões do real, vistas como fundo e forma, dentro de um movimento constante de territorialização e desterritorialização, de fluxos interiores e exteriores dos corpos e das identidades, bem como das formas de representação do mundo.

Com a aparição de Manhã, Agrippino explora seus pequenos gestos diante de sua própria imagem refletida no espelho, tendo o céu azul e a luz do sol ao fundo. É como se o filme recomeçasse. Esses gestos se contrapõem à saturação do quadro, que, mais uma vez, desterritorializa a imagem e, portanto, a representação. A câmera dedica-se, então, a fazer o espectador sentir a força empregada pela criança em seus pequenos movimentos, como o de tentar engatinhar, ficar de pé, sugar ou tocar o bico do seio da mãe, equilibrarse em seus primeiros passos e experiências no mundo.

Figura 3

Em tons violáceos, a filha do casal, Manhã, é filmada em seus primeiros movimentos, e sua aparição é associada à ideia de um recomeçar do mundo.

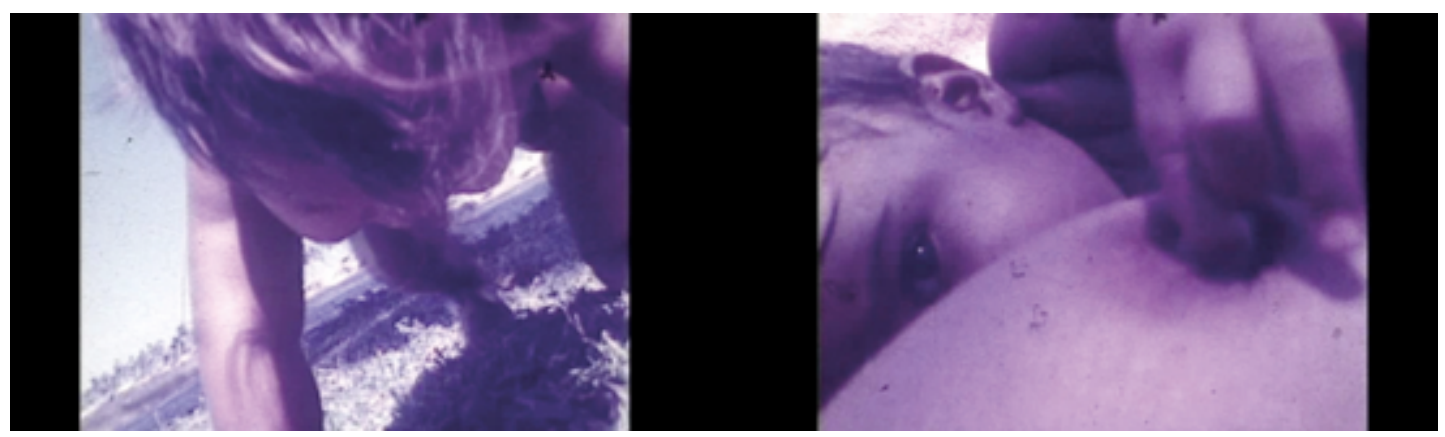

Fonte: Céu sobre água, 1978, 20min28s. 
Em uma das sequências mais expressivas do filme, Agrippino filma primeiro a paisagem distorcida no espelho d'água, para depois enquadrar aos poucos os reflexos de Maria Esther, já sem a barriga da gravidez, caminhando em direção à câmera. Ela surge como uma aparição. Conforme caminha, movimenta a água rasa no chão, seu corpo e a paisagem perdem contornos e definição, aparecem camadas de cores e formas pouco precisas, que oscilam e se modificam de acordo com o seu caminhar e as transformações da luz na água. A imagem de Maria Esther, então, dissolve-se com a paisagem.

Como numa pintura impressionista, observamos a supressão dos contornos e a inversão da prioridade do desenho sobre as cores, que são consideradas em sua própria materialidade, para captar, através da sensação, fragmentos do mundo. A técnica pictórica é entendida como uma forma de conhecimento, e o espaço é criado a partir da fricção entre as cores complementares, que fazem vibrar as formas. Em Arembepe, Agrippino buscava, como alguns pintores do final do século XIX, apreender a "impressão luminosa e transparência da atmosfera e da água com notas cromáticas puras" (ARGAN, 1992, p.75).

Figura 4

Maria Esther surge na paisagem como uma aparição.

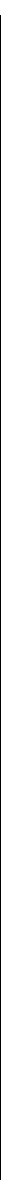

Fonte: Céu sobre água, 1978, 22min16s. 
No entanto, mais do que buscar uma sensação visual, envolvendo os objetos em um invólucro luminoso, de forma a fazê-los desaparecer em seu próprio peso (MERLEAU-PONTY, 2004, p. 129), Agrippino, a exemplo de Cézanne, toma as cores como algo profundamente corporal, sem fazer distinção entre o tátil e a visão, o corpo e o pensamento. Merleau-Ponty observa que, ao recuperar as cores terrosas, os ocres e os pretos, o pintor devolvia a materialidade, ou a corporeidade das coisas, por trás da atmosfera e da sensação. Os contornos do real deveriam nascer da cor, de forma a revelar a espessura do mundo.

Em sua pintura, pontua o filósofo, Cézanne buscava “dar a impressão de um objeto nascente, de um objeto em vias de aparecer, em vias de aglomerar-se sob os nossos olhos", acompanhando, pela modulação das cores, a "intumescência dos objetos" (2004, p.129). Perseguia, assim, a impressão do movimento e, ao mesmo tempo, uma aparição. O corte está, como argumenta o autor, entre a ordem espontânea das coisas percebidas e a ordem humana das ideias e das ciências; daí o interesse por um mundo primordial, pela natureza e por sua origem, bem como o aspecto quase sempre inumano de sua pintura, que busca devolver a ciência à natureza.

Em Agrippino, por sua vez, trata-se da relação com o sagrado. O corpo feminino é o elemento central de conexão com a natureza, a partir de uma pesquisa do movimento no cinema e na dança; de certa forma, já prefigurada na obra de Cézanne, na qual o arranjo das cores traduz o "indizível do mundo" e "a expressão daquilo que existe é uma tarefa infinita" (2004, p.131).

Na sequência final de Céu sobre água, novamente nadando e fazendo movimentos de costas na água, o corpo nu de Maria Esther ressurge, desmistificado dos códigos e estereótipos de gênero que sexualizam e erotizam, numa palavra, objetificam, o corpo da mulher. No último plano, suas pernas e sua pelve, tomadas por camadas vívidas, densas e luminosas de amarelos, abrem-se novamente, desta vez para o espectador.

Figura 5

A primeira e última imagem de Céu sobre água.

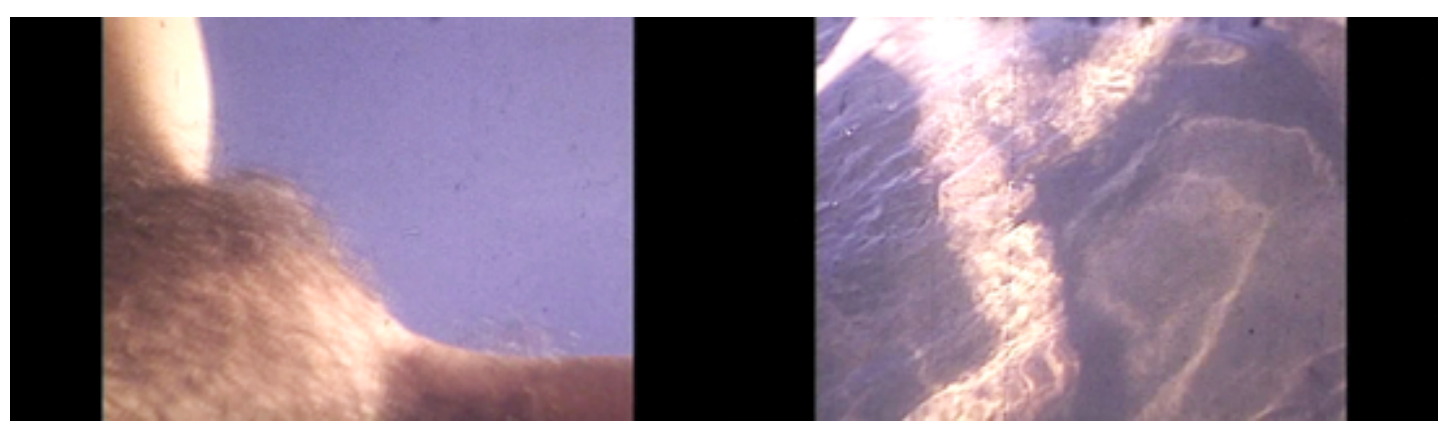

Fonte: Céu sobre água, 1978, 22min16s. 
Em Céu sobre água, o corpo grávido de Maria Esther vibra às forças da natureza. O corpo feminino é visto como parte de seus fluxos e de suas dinâmicas em sintonia com a dimensão do sagrado, que expressa-se subjetivamente através da luz, das cores e da relação com a paisagem. Se, em um primeiro momento, a barriga prenhe de vida de Maria Esther é vista como paisagem, em outro é pura matéria viva, devir. Em Arempebe, Agrippino e Maria Esther recriam, por meio das cores, da cultura e do corpo, o mundo que desejam para Manhã.

\section{Notas}

1. "A cor anda. E, enquanto anda, ela muda" (tradução nossa).

2. Em depoimento concedido durante o evento "Cinema Brasileiro - Debate sobre José Agrippino de Paula”, no Museu da Imagem e do Som, São Paulo, 1988, Maria Esther refere-se ao filme como um "cinepoema" (GIANETTI, 2015, p.208).

3. A referência à música de Ravi Shankar aparece nos créditos do encarte do DVD Cinema Marginal Brasileiro 6 (2010), dedicado a José Agrippino de Paula. No entanto, em nenhuma das fontes consultadas foi possível identificar o título da música. Além do curta Céu sobre água (1978) e do média Maria Esther: danças na África (1972), realizados em Super-8, o DVD traz o seu primeiro e único filme de longa-metragem, Hitler de III Mundo (1968).

4. O CD foi lançado com a caixa Exu 7 Encruzilhadas (2012), que traz também um DVD com os filmes em Super-8 Candomblé do Togo (1972) e Candomblé do Dahomey (1972). O texto de Arnaldo Antunes está no encarte.

5. Beauvais (2009) afirma que Agrippino e Maria Esther já viviam juntos quando ela monta os dois espetáculos com o grupo Móbile (1964 e 1965) e ele escreve seus dois primeiros livros (1965 e 1967). No entanto, na descrição que Agrippino faz desse encontro, ele parece referir-se ao ensaio Improvisação sobre um tema de raga da noite, que, segundo Giannetti (2015), estreia em agosto de 1965, no Teatro Ruth Escobar.

6. Depoimento de José Agrippino em entrevista concedida a Maria Theresa Vargas, 1979. Arquivo Multimeios, Centro Cultural São Paulo, São Paulo, SP (GIANNETTI, 2015).

7. É notório o quanto, a partir dos filmes feitos na África e, em particular, de Céu sobre água, Agrippino distancia-se de uma poética pautada pelo excesso, pelo humor e pelo grotesco, que marcam em grande medida seus livros e espetáculos.

8. O fotográfo e etnógrafo Pierre Verger investigou as relações entre a Bahia e países africanos do Golfo do Benim, antigo Dahomey, no livro Fluxo e refluxo do tráfico de escravos entre o Golfo 
do Benin e a Baía de Todos os Santos dos séculos XVII a XIX, publicado na França em 1968 e traduzido no Brasil apenas em 1987.

9. Depoimento de Jorge Mautner sobre Agrippino após seu retorno da África. De acordo com ele, Agrippino "falava insistentemente sobre a linguagem oculta e manifesta dos tambores, em suas batucadas sagradas sempre iguais e diferentes, seus infinitos significados e variações". In: Encarte do DVD Exu 7 Encruzilhadas (2012).

10. Em depoimento no Extra do DVD Cinema Marginal e suas fronteiras o6 (2010), dedicado a José Agrippino de Paula, Jorge Bodansky conta que filmava sem nenhuma orientação do ponto de vista da captação da imagem e que Agrippino fez o filme sem qualquer experiência anterior com a realização cinematográfica.

11. Depoimento no DVD Exu 7 Encruzilhadas (2012).

12. O livro é apresentado como um romance, mas é baseado em histórias vividas pelo autor em Arembepe. Agrippino e Maria Esther recebem os pseudônimos de Zé Agostinho e Bia, mas com referências diretas ao livro Panamérica, à peça Nações Unidas e ao filme Hitler de III Mundo, além da gravidez de Maria Esther, com descrição minuciosa das filmagens que presenciou.

13. É possível que seja uma raga da manhã, já que Maria Esther, desde seus primeiros espetáculos, manteve uma relação muito próxima com a música clássica hindu de Ravi Shankar, tendo criado, na segunda montagem do grupo Móbile, em 1965, o solo Improvisações sobre um raga da noite.

14. Tradução nossa para original em inglês: "Color walks. And as it walks, so it changes. It is not something daubed onto a preexisting shape, filling a form, because colors have their own 'form', giving life and light to the world".

15. "When we see a color, we are actually seeing a play with light in, through, and on a body, the body of color itself".

16. A pergunta que dá título ao livro de Taussig, What color is the sacred? (2009), é atribuída por ele a Michel Leiris, escritor, etnólogo e crítico de arte francês ligado ao movimento surrealista, sub-editor da lendária revista Documents, editada entre 1929 e 1930, pelo filósofo e escritor Georges Bataille.

\section{Referências}

ARGAN, Giulio Carlo. Arte moderna. Do iluminismo aos movimentos contemporâneos. São Paulo: Companhia das Letras, 1992.

BEAUVAIS, Yann. A gente saía de manhã sem ter uma ideia (Sobre José Agrippino de Paula). Lugar Comum. Estudos de Mídia, Cultura e Democracia, n.28. Rio de Janeiro: Rede Universidade Nômade, 2009. 
BONDAZKY conta Agrippino. Extra DVD Exu 7 Encruzilhadas. São Paulo: SESC-SP, 2012. 19min,38s, som, cor.

CANDOMBLÉ no Dahomey. Direção: José Agrippino de Paula. Dahomey: 1972. 22min.40s, som, cor, Super-8. DVD Exu 7 Encruzilhadas. São Paulo: SESC-SP, 2012.

CANDOMBLÉ no Togo. Direção: José Agrippino de Paula. Dahomey: 1972. 20min., som, cor, Super-8. DVD Exu 7 Encruzilhadas. São Paulo: SESC-SP, 2012.

CÉU sobre água. Direção: José Agrippino de Paula. Arembepe: 1978. 20 min., som, cor, Super-8. DVD Cinema Marginal Brasileiro 6 - José Agrippino de Paula. São Paulo: Heco Produções, 2010.

GIANNETTI, Julia. A dança marginal de Maria Esther Stockler: um olhar imagético. 2015. 264 páginas. Dissertação (Mestrado) - Universidade Estadual de Campinas (UNICAMP), Campinas, 2015.

HITLER $3^{\circ}$ Mundo. Direção: José Agrippino de Paula. São Paulo: 1968. 90 min., preto e branco, som, 16mm. DVD Cinema Marginal Brasileiro 6 - José Agrippino de Paula. São Paulo: Heco Produções, 2010.

HOISEL, Beto. Naquele tempo, em Arembepe. Salvador: Século 22, 2003.

MARIA Esther: danças na África. Direção: José Agrippino de Paula e Maria Esther Stockler. África: 1972. 40 min., som, cor, Super-8. DVD Cinema Marginal Brasileiro 6 José Agrippino de Paula. São Paulo: Heco Produções, 2010.

MAUTNER, Jorge. Depoimento. Encarte DVD Exu 7 Encruzilhadas. São Paulo: SESC -SP, 2012.

MORAES, Felipe Augusto de. A arte-soma de José Agrippino de Paula. 2011. 164 páginas. Dissertação (Mestrado) - Universidade de São Paulo (USP), São Paulo, 2011.

MERLEAU-PONTY. Maurice. A dúvida de Cézanne. In: O olho e o espírito. São Paulo: Cosac Naify, 2004.

RISÉRIO, Antonio. Duas ou três coisas sobre a contracultura no Brasil. In: Anos 7O: trajetórias. São Paulo: Iluminuras: Itaú Cultural, 2005.

TAUSSIG, Michael. What color is the sacred? Chicago and London: The University of Chicago Press, 2009. 
VELOSO, Caetano. Verdade tropical. São Paulo: Companhia das Letras, 1997.

VERGER, Pierre. Fluxo e Refluxo do tráfico de escravos entre o Golfo do Benin e a Bahia de Todos os Santos: dos séculos XVII a XIX. São Paulo: Corrupio, 1987.

VIVEIROS DE CASTRO, Eduardo. Metafísicas canibais. São Paulo: Cosac Naify, 2015.

ZÉ, Tom. Depoimento. Encarte DVD Exu 7 Encruzilhadas. São Paulo: SESC-SP, 2012.

Recebido em: 31/01/2017

Aprovado em: 02/05/2018

Publicado em: 20/05/2019 